\title{
Ambulatory blood pressure and Doppler echocardiographic indexes of borderline hypertensive men presenting an exaggerated blood pressure response during dynamic exercise
}

F.L. Herkenhoff,

E.C. Vasquez, J.G. Mill and E.G. Lima
Departamento de Ciências Fisiológicas, Centro Biomédico, Universidade Federal do Espírito Santo, Vitória, ES, Brasil

\section{Correspondence \\ F.L. Herkenhoff \\ Departamento de Ciências Fisiológicas Centro Biomédico, UFES \\ Av. Mal. Campos, 1468 \\ 29040-090 Vitória, ES \\ Brasil \\ Fax: +55-27-3335-7330 \\ E-mail: ferherk@npd.ufes.br \\ Research supported by Companhia \\ Vale do Rio Doce.}

Received November 4, 1999 Accepted July 10, 2001

\section{Abstract}

Borderline hypertension (BH) has been associated with an exaggerated blood pressure (BP) response during laboratory stressors. However, the incidence of target organ damage in this condition and its relation to BP hyperreactivity is an unsettled issue. Thus, we assessed the Doppler echocardiographic profile of a group of $\mathrm{BH}$ men $(\mathrm{N}=36)$ according to office BP measurements with exaggerated BP in the cycloergometric test. A group of normotensive men $(\mathrm{NT}, \mathrm{N}=36)$ with a normal BP response during the cycloergometric test was used as control. To assess vascular function and reactivity, all subjects were submitted to the cold pressor test. Before Doppler echocardiography, the BP profile of all subjects was evaluated by $24-\mathrm{h}$ ambulatory BP monitoring. All subjects from the NT group presented normal monitored levels of BP. In contrast, 19 subjects from the original BH group presented normal monitored BP levels and 17 presented elevated monitored BP levels. In the NT group all Doppler echocardiographic indexes were normal. All subjects from the original BH group presented normal left ventricular mass and geometrical pattern. However, in the subjects with elevated monitored BP levels, fractional shortening was greater, isovolumetric relaxation time longer, and early to late flow velocity ratio was reduced in relation to subjects from the original $\mathrm{BH}$ group with normal monitored $\mathrm{BP}$ levels $(\mathrm{P}<0.05)$. These subjects also presented an exaggerated BP response during the cold pressor test. These results support the notion of an integrated pattern of cardiac and vascular adaptation during the development of hypertension.

\section{Key words}

- Borderline hypertension

- Cardiovascular reactivity

- Laboratory stress test

- Doppler echocardiography

\section{Introduction}

It is well established that cardiovascular structural and functional abnormalities occurring in essential hypertension are independently related to an increased risk of cardiovascular morbidity and mortality (1).
However, the association between conventional office blood pressure (BP) level and left ventricular (LV) structural and functional adaptations is not strong (2). In contrast, ambulatory blood pressure monitoring (ABPM) levels, which are influenced by a variety of physical, psychological and be- 
havioral factors, are closely related to cardiovascular adjustments (3). Impairment of systolic function eventually occurs late in the course of essential hypertension (4). In contrast, LV hypertrophy and alterations in diastolic function appear earlier in essential hypertension (5).

There are also observations supporting the concept that BP variation depends critically on the level of physical and mental activity (6). Nevertheless, the role of BP variability in target organ damage is still a controversial issue. It has been reported that cardiovascular hyperreactivity to physical (7) and mental (8) stress plays a pathophysiological role in cardiovascular disease. Thus, the possibility that a greater elevation of $\mathrm{BP}$ during ordinary or exceptional life situations plays an important role in the development of hypertension is conceivable.

Laboratory stressing maneuvers have been designed for early detection of hypertension-prone subjects (9). In longitudinal studies, these tests have provided predictive information about the future incidence of hypertension (10). The assumption is that the cardiovascular responses in the laboratory environment correspond to BP behavior in everyday life conditions $(11,12)$. Dynamic exercise tests have been more usually employed to evaluate cardiovascular function (13). In recent longitudinal studies, however, an exaggerated BP response during dynamic exercise provided predictive information about the future incidence of hypertension and related target organ damage $(14,15)$. The cold pressor test (CPT) is employed to evaluate vascular functions in normotensive and hypertensive men (16). An exaggerated elevation of BP during this test is primarily determined by an increased vasoconstrictive response (17).

Borderline hypertension has been frequently associated with both an exaggerated $\mathrm{BP}$ response in the presence of laboratory stressors and changes in cardiovascular structure and function $(18,19)$. In some studies, however, paradoxical results have been obtained $(20,21)$. These inconsistent results may be related to an inappropriate assessment of the BP status of borderline hypertensive subjects or to an imprecise measurement of cardiovascular reactivity during laboratory stressors. ABPM allows a more accurate assessment of $\mathrm{BP}$ profile $(22,23)$. By avoiding the white-coat effect, ABPM may help resolve controversial aspects regarding the relations between BP levels, cardiovascular reactivity and target organ damage.

Few studies have employed Doppler echocardiography to assess the impact of BP and reactivity of the cardiovascular system in borderline hypertension. Thus, the present investigation was conducted to assess cardiac structure and function in a group of borderline hypertensive men with an exaggerated BP response during the cycloergometric test (CET). Vascular reactivity and function of these subjects were also assessed by the CPT. Before Doppler echocardiographic assessment, 24-h ABPM was recorded in order to determine the BP profile of the subjects.

\section{Material and Methods}

\section{Study population and sample}

The target group consisted of 36 borderline hypertensive $(\mathrm{BH})$ men $(23,24)$ according to casual office BP measurement of systolic blood pressure (SBP, $140-150 \mathrm{mmHg}$ ) and/or diastolic blood pressure (DBP, 90-100 $\mathrm{mmHg}$ ), presenting an exaggerated $\mathrm{BP}$ response during CET (SBP $\geq 220 \mathrm{mmHg}$ ). The control group consisted of 36 normotensive (NT) men (casual office SBP $<140$ and DBP $<90 \mathrm{mmHg}$ ), presenting a normal BP response (SBP $\leq 220 \mathrm{mmHg}$ ) during CET. All subjects investigated were 35 to 49 years of age. They were selected from 982 male employees of a local mining and transport company (Companhia Vale do Rio Doce) attending the Research Center on Work and Exer- 
cise, State University of Espírito Santo, in 1996-1997 for routine cardiovascular evaluation. The initial screening procedure consisted of a clinic cardiac examination by a physician. A questionnaire on personal data, health history, work activity, smoking and alcohol consumption was completed with the help of a nurse. Subjects with known or suspected cardiovascular disease, diabetes mellitus, locomotion system disorders, and pulmonary, renal, liver or other chronic diseases were excluded. Weight, height and other anthropometric measures were assessed with subjects in their underclothes.

The study was performed in accordance with the regulations approved by the Ethics Committee for Human Research of the State University of Espírito Santo. All subjects signed an informed consent form after the objectives and procedures of the study were explained to them.

\section{Office blood pressure measurements}

BP determinations were conducted as previously described (25). A physician using standardized conditions of position, rest and cuff size obtained BP measurements. Casual office SBP and DBP were measured by auscultation with a mercury column sphygmomanometer taken respectively as the first and fifth Korotkoff sound. The protocol was as follows: $10 \mathrm{~min}$ of supine rest, with $\mathrm{BP}$ measured at 5 and $10 \mathrm{~min} ; 10 \mathrm{~min}$ of seated rest, with BP measured at 5 and $10 \mathrm{~min}$. The lowest level of seated BP was recorded. In cases in which there was a deviation of $\geq 5$ $\mathrm{mmHg}$ between supine and seated readings, BP measurements were repeated until consistent measurements were obtained.

\section{Cycloergometric test}

Subjects were instructed to abstain from forceful physical activity and to avoid excessive food consumption and stressful situations on the day scheduled for the test. Smok- ing and alcoholic beverages were also to be avoided. The initial protocol consisted of anamnesis, clinical examination and a resting 12-lead standard electrocardiogram (ECG). All subjects performed a symptomlimited continuous exercise on an electrically braked bicycle (ECAFIX). The starting workload was 50 watts and increments were by steps of 25 watts every $3 \mathrm{~min}$. The pedaling rate was maintained as close to $60 \mathrm{rpm}$ as possible to achieve maximal mechanical efficiency and standardization. Subjects were encouraged to continue exercising until exhaustion. Accepted criteria were used for terminating the test (26). Pre-test BP was measured after 10 min of supine rest. During the test, BP was measured twice (after 1.5 and $3 \mathrm{~min}$ ) during each workload. After the test, the recovery BP level was measured at the fourth minute with the subject still seated on the bicycle. BP reactivity was calculated for each workload by subtracting the pre-test level from the highest BP level measured during the specific workload. ECG tracings were recorded from the MC5, V2 and D2 leads on a 3-channel ECG monitor (RG-300 FUNBEC) before performing the exercise test, during change in posture, respiratory maneuvers and at the third minute of each workload. A 3-channel oscilloscope (MM305FUNBEC) monitored the ECG records and heart rate (HR) continuously. HR was recorded at the third minute of each workload. After the test, the standard 12-lead ECG was repeated and ECG tracings were monitored with an oscilloscope until the fourth minute of the recovery period. The following parameters were evaluated: $\mathrm{BP}, \mathrm{HR}$, and maximal oxygen consumption $\left(\mathrm{VO}_{2} \mathrm{max}, \mathrm{ml} \mathrm{kg}^{-1}\right.$ $\mathrm{min}^{-1}$ ) according to the formula of Bruce (27) and the maximal double product (DPmax) by multiplying SBP $x$ HR in the last workload (mmHg bpm 10-2).

\section{Ambulatory blood pressure monitoring}

ABPM was performed with an oscillo- 
metric device (Spacelabs-90207) applied to all patients between 8:00 and 9:00 am after a 10-min rest according to accepted criteria (28). The cuff was fixed on the nondominant arm and three BP readings were taken concomitantly with a standard sphygmomanometric reading to ensure that the average of the three sets of values did not differ by more than $5 \mathrm{mmHg}$. The device was set to record automatic BP readings at 20-min interval during the daytime (usually from 9:00 am to $11: 00 \mathrm{pm}$ ) and at 30-min interval during the night-time (usually from 11:00 pm to 9:00 am). The patient was sent home with instructions to hold the arm immobile during the measurements, to keep a diary of main daily activities and to return to the laboratory approximately $24 \mathrm{~h}$ later. After entering the data of each patient into a computer, the accuracy of the device was again verified against previously specified BP levels of a mercury sphygmomanometer. ABPM was always performed on a workday. The following parameters were assessed: data quality; 24-h, daytime and night-time BP and HR means; leisure and occupational BP and HR means, calculated directly from the individual diary; $\mathrm{BP}$ and $\mathrm{HR}$ variability during these periods, and daytime and night-time BP load. The BP profile of each subject was established according to reference standards (28).

\section{Cold pressor test}

The CPT was performed as classically described (29). The nondominant hand was immersed up to the wrist in ice-cold water for 3 min. Pre-test BP was measured after 10 min of supine rest. The pre-test BP was recorded immediately after description of the procedure. During the CPT, BP was taken after $30 \mathrm{~s}$ of stimulation and measured twice with a 1-min interval. The highest level of SBP and DBP observed during the procedure was recorded. The post-test level of BP was recorded 2 min after the end of the test.
BP reactivity was calculated by subtracting the highest level recorded during the test from the pre-test level.

\section{Doppler echocardiographic assessment}

All subjects underwent a complete echocardiographic assessment with a commercially available phased-array scanner (ESAOTE S.I.M.-7000) equipped with 2.5 and $3 \mathrm{MHz}$ transducers coupled to a strip recorder. All tracings were obtained and read by a single observer blinded to clinical characteristics and BP status of the subjects under observation. Data were recorded on videotape and analyzed on-line from frozen frames by the apparatus' own software. Hardcopy strips were obtained with a photograph device (Cannon LS-120) coupled to the echocardiographic equipment. Standard oneand two-dimensional echocardiographic images were recorded from all subjects. These recordings were taken with care to place the cursor just distal to the mitral valve tips. Signal damping was adjusted to optimal identification of endocardial and epicardial interfaces. The overall one- and two-dimensional (apical four- and two-chamber) measurements were performed according to recommendations of the American Society of Echocardiography (30). LV end diastolic diameter (LVDd), LV end systolic diameter (LVSd), LV posterior wall thickness (PWT), interventricular septal thickness (IVST) and left atrial diameter were determined. Corrected LV mass was calculated using the equation developed by Devereaux et al. (31). It was indexed for the body surface area and expressed as $\mathrm{g} / \mathrm{m}^{2}$. Endocardial fractional shortening (FS) was calculated using the formula $\mathrm{FS}=[(\mathrm{LVDd}-\mathrm{LVSd}) / \mathrm{LVDd}] \mathrm{x}$ 100; the relative wall thickness (RWT) was calculated as twice the PWT divided by LVDd $x$ 100. Indexed LV mass $\leq 125 \mathrm{~g} / \mathrm{m}^{2}$ and RWT $\leq 45$ were used for reference of normality of the LV mass and geometrical pattern, respectively. Doppler assessment was 
performed as previously described (32). The transducer was held at the cardiac apex. The Doppler beam was aligned parallel to the presumed mitral inflow, and the sample was placed at the level of the tips of the mitral valve leaflets. Signals that demonstrated the highest peak velocities and narrowest spectral dispersion were selected. Mitral inflow was recorded on videotape at a speed of 100 $\mathrm{mm} / \mathrm{s}$ for subsequent analysis. LV diastolic function indexes such as early to late peak flow velocity ratio (E/A) and isovolumetric relaxation time (IVRT) were assessed.

\section{Statistical analysis}

Statistical analyses were performed using the GB-STAT for Windows version 6.0 software licensed to the Federal University of Espírito Santo. Variable responses during the laboratory tests were compared by repeated measures analysis of variance (ANOVA). Data were compared by a standard Student $t$-test for independent samples or standard ANOVA followed by the Tukey test. Results are reported as means $\pm \mathrm{SD}$ or SEM and the level of significance was set at $\mathrm{P}<0.05$.

\section{Results}

\section{Characteristics of the groups}

Table 1 shows casual office BP and HR, anthropometric characteristics, maximal oxygen uptake $\left(\mathrm{VO}_{2} \max \right)$ and maximal double product (DPmax) recorded for the $\mathrm{BH}$ and NT groups. By definition, the BH and NT groups presented different casual office BP values. The anthropometric profile was similar in both groups, with no difference in age, weight, height or body mass index. DPmax and $\mathrm{VO}_{2}$ max were also similar. These values were expected since no subject was involved in physical conditioning and all individuals held office jobs without physical activity. Six subjects declared smoking habits (3 in each group) and 12 (6 in each group) declared moderate alcoholic ingestion.

\section{Cycloergometric test}

BH subjects presented a higher maximal SBP level than NT subjects in the CET (238 \pm 11 vs $200 \pm 10 \mathrm{mmHg}, \mathrm{P}<0.05)$. Maximal DBP level, however, was similar in the two groups ( $84 \pm 8$ vs $82 \pm 5 \mathrm{mmHg}$, not significant). Even when the scores for change in BP (workload minus pre-test level) were calculated (Figure 1), BH subjects presented a higher SBP response than NT subjects from 75 watts to maximum workload. The DBP response was similar for the two groups at all workloads. During recovery, however, it was below pre-test level in the NT group and above it in the BH group. HR response was similar throughout the CET.

\section{Twenty-four-hour ambulatory blood pressure monitoring}

ABPM data are summarized in Table 2. $\mathrm{BH}$ subjects presented higher levels of $\mathrm{BP}$ than the NT subjects during the 24-h ABPM.

Table 1. Casual office systolic blood pressure, diastolic blood pressure and heart rate, and other characteristics of subjects from the normotensive (NT) and borderline hypertensive $(\mathrm{BH})$ groups.

\begin{tabular}{lcc}
\hline & BH & NT \\
\hline SBP (mmHg) & $143 \pm 5^{*}$ & $126 \pm 5$ \\
DBP (mmHg) & $94 \pm 4^{*}$ & $82 \pm 4$ \\
HR (bpm) & $60 \pm 9$ & $62 \pm 8$ \\
Age (years) & $43 \pm 4$ & $42 \pm 3$ \\
Age range (years) & $35-50$ & $36-49$ \\
Height (cm) & $174 \pm 6$ & $171 \pm 6$ \\
Weight (kg) & $76 \pm 9$ & $78 \pm 9$ \\
BMI (kg/m²) & $26 \pm 4.5$ & $27 \pm 2$ \\
VO ${ }_{2}$ max (ml kg min $\left.^{-1}\right)$ & $26 \pm 3.7$ & $27 \pm 4$ \\
DPmax (mmHg bpm 10-2) & $384 \pm 42$ & $378 \pm 36$
\end{tabular}

SBP, systolic blood pressure; DBP, diastolic blood pressure; HR, heart rate; $\mathrm{BMI}$, body mass index; $\mathrm{VO}_{2}$ max, maximal oxygen uptake; Dpmax, maximal double product. Values other than age range are means $\pm \mathrm{SD}(\mathrm{N}=36)$. $* \mathrm{P}<0.05$ compared to the NT group (Student t-test). 

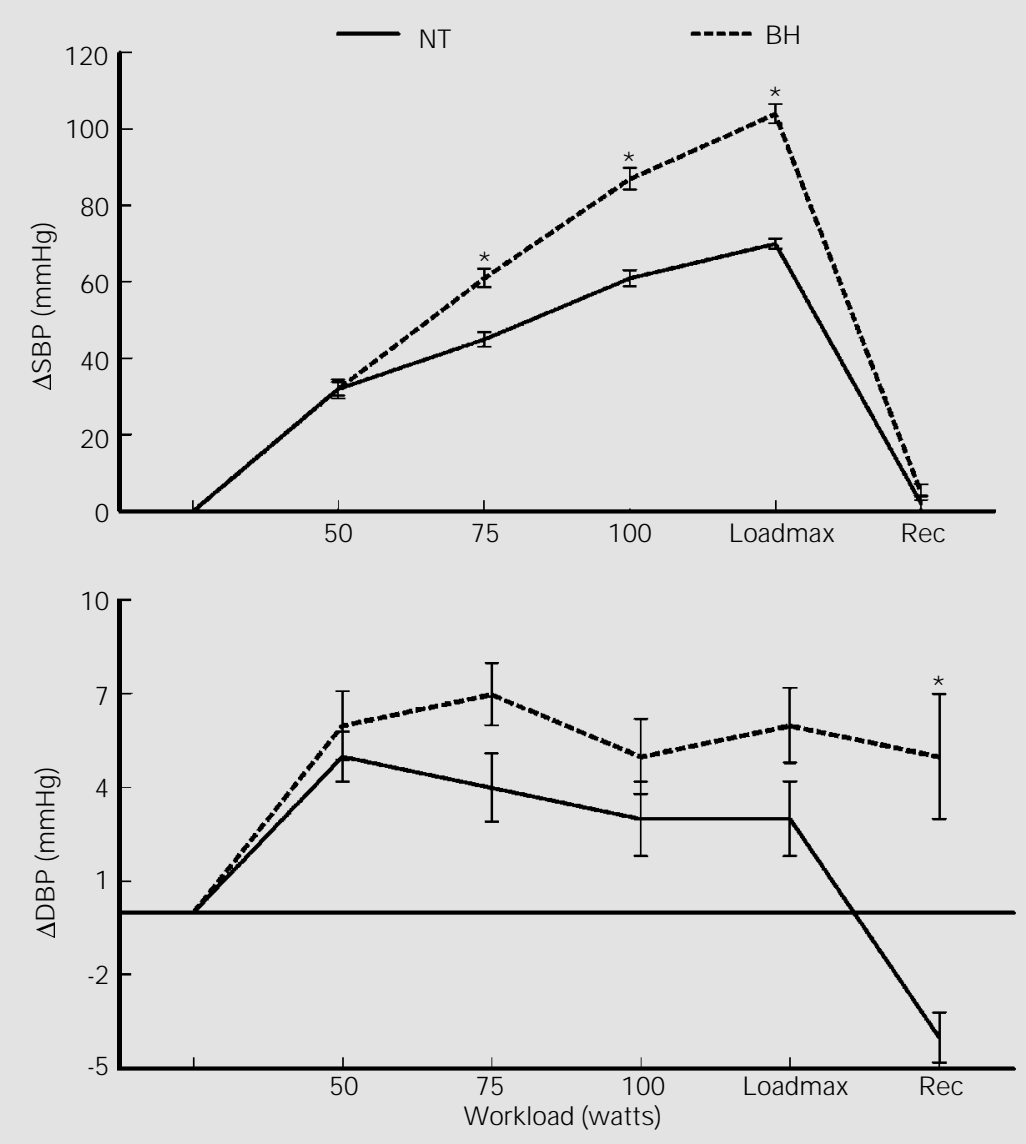

Figure 1. Cycloergometric test. Change in systolic blood pressure ( $\triangle \mathrm{SBP}$ ) and diastolic blood pressure $(\triangle \mathrm{DBP})$ recorded for the normotensive $(\mathrm{NT})$ and borderline hypertensive $(\mathrm{BH})$ groups. Loadmax refers to the maximal workload attained during the test, usually 125 and eventually 150 watts. Rec refers to the recovery period. Values are reported as means \pm SEM. $* \mathrm{P}<0.05$, BH compared to NT at the specified workload (Student t-test).

Table 2. Twenty-four-hour ambulatory blood pressure monitoring (ABPM) of systolic blood pressure, diastolic blood pressure and heart rate in the normotensive (NT) and borderline hypertensive $(\mathrm{BH})$ groups.

\begin{tabular}{lccccccc}
\hline ABPM period & \multicolumn{4}{c}{ NT } & & \multicolumn{3}{c}{ BH } \\
\cline { 2 - 4 } \cline { 7 - 8 } & SBP & DBP & HR & & SBP & DBP & HR \\
\hline 24-h & $126 \pm 6$ & $82 \pm 4$ & $76 \pm 10$ & & $134 \pm 8^{*}$ & $86 \pm 6^{*}$ & $74 \pm 7$ \\
Daytime & $128 \pm 6$ & $84 \pm 4$ & $76 \pm 10$ & & $136 \pm 8^{*}$ & $87 \pm 6^{*}$ & $76 \pm 8$ \\
Night-time & $114 \pm 7$ & $75 \pm 6$ & $67 \pm 8$ & & $125 \pm 8^{*}$ & $78 \pm 7^{*}$ & $67 \pm 7$ \\
Sleep time & $110 \pm 6$ & $68 \pm 4$ & $63 \pm 8$ & & $116 \pm 8^{*}$ & $75 \pm 8^{*}$ & $61 \pm 6$ \\
Leisure time & $127 \pm 6$ & $84 \pm 4$ & $76 \pm 10$ & & $133 \pm 8^{*}$ & $85 \pm 6^{*}$ & $75 \pm 9$ \\
Work time & $129 \pm 9$ & $84 \pm 5$ & $78 \pm 10$ & & $134 \pm 9^{*}$ & $87 \pm 7^{*}$ & $78 \pm 11$
\end{tabular}

SBP, systolic blood pressure $(\mathrm{mmHg})$; DBP, diastolic blood pressure $(\mathrm{mmHg}) ; \mathrm{HR}$, heart rate (bpm). Values are reported as means $\pm \mathrm{SD}(\mathrm{N}=36)$.

$* \mathrm{P}<0.05, \mathrm{BH}$ versus NT (Student t-test).
Individual records, however, showed that of the 36 originally $\mathrm{BH}$ patients (according to office BP measurements), 19 actually presented normal monitored BP levels and 17 elevated monitored BP levels. The original BH group was then divided into two groups, one including the subjects with normal monitored BP levels $\left(\mathrm{BH}_{1}\right)$ and the other including the subjects with elevated monitored $\mathrm{BP}$ levels $\left(\mathrm{BH}_{2}\right)$ (Table 3$)$.

\section{Cold pressor test}

Results of the CPT are presented in Figure 2. SBP and DBP responses were higher during the testing period among $\mathrm{BH}$ subjects with elevated monitored $\mathrm{BP}\left(\mathrm{BH}_{2}\right)$ than in the $\mathrm{BH}$ subjects with normal monitored $\mathrm{BP}$ $\left(\mathrm{BH}_{1}\right)$ or the NT subjects. No differences were recorded between groups during the test, pre-test and post-test periods. HR behavior was similar in all groups throughout the CPT. Figure 3 shows that 24-h ABPM SBP and DBP were positively correlated with the maximum values of SBP and DBP recorded during the $\mathrm{CPT}$ in the $\mathrm{BH}_{2}$ group but not in the $\mathrm{BH}_{1}$ group.

\section{Doppler echocardiography}

Doppler echocardiographic indexes for the NT, $\mathrm{BH}_{1}$ and $\mathrm{BH}_{2}$ groups are presented in Table 4. LV structure and geometric pattern were similar and normal in all groups: no significant difference was found in LVDd, LVSd, PWT, IVST or RWT. LV mass was also normal and similar in all groups. In contrast, systolic function index (FS) was higher in the $\mathrm{BH}_{2}$ than in the $\mathrm{BH}_{1}$ and NT groups. Diastolic function indexes (IVRT and $\mathrm{E} / \mathrm{A}$ ratio) were also altered in the $\mathrm{BH}_{2}$ group in relation to the other two groups.

\section{Discussion}

The present study was designed to evaluate the cardiovascular geometric pattern and 
the functional indexes of a group of $\mathrm{BH}$ subjects (according to casual office BP measurements) presenting an exaggerated BP response during a dynamic exercise test. Studies on BP reactivity usually do not take into account that office and laboratory BP measurements are influenced by environmental conditions (33). In analogy to the white-coat effect noticed during office BP measurement (22), BP levels measured before laboratory tests may be inadequate to assess $\mathrm{BP}$ profile and cardiovascular reactivity. In this study, all subjects were submitted to ABPM. Therefore, the relations between both BP and cardiovascular reactivity and Doppler echocardiographic indexes could be more properly evaluated.

Twenty-four-hour ABPM showed that the monitored BP levels were actually suggestive of hypertension in $50 \%$ of the BH subjects and suggestive of normotension in the other $50 \%$. Diastolic functional indexes were altered in the subjects with elevated monitored BP level: IVRT was extended and above the age-predicted value and the E/A ratio was also elevated (34). Although changes in diastolic function have been reported even in young men with high-normal BP (35), they are usually described in established hypertension. The usual pattern is a reduced E/A ratio and a protracted IVRT (34). These abnormalities have been described in BH men in some studies $(36,37)$ but not in other (38). The results of the present study indicate that these discrepant results may be related to an inappropriate evaluation of the BP profile of these subjects.

A systolic function index (FS) was also enhanced in the subjects with elevated monitored BP levels. An elevated FS is suggestive of an increased sympathetic drive, but could also be a physiological response to a steadily elevated afterload, frequently associated with elevated vascular resistance (39). This last assumption is supported by the fact that these subjects also presented an exaggerated
Table 3. Ambulatory blood pressure monitoring (ABPM) data showing that some borderline hypertensive subjects presented normal blood pressure levels during 24-h monitoring $\left(\mathrm{BH}_{1}\right)$ while others showed elevated blood pressure levels during $24-\mathrm{h}$ monitoring $\left(\mathrm{BH}_{2}\right)$.

\begin{tabular}{lccccccc}
\hline \multirow{2}{*}{ ABPM period } & \multicolumn{3}{c}{$\mathrm{BH}_{1}(\mathrm{~N}=19)$} & & \multicolumn{3}{c}{$\mathrm{BH}_{2}(\mathrm{~N}=17)$} \\
\cline { 2 - 4 } \cline { 6 - 8 } & SBP & DBP & HR & & SBP & DBP & HR \\
\hline 24-h & $128 \pm 4$ & $81 \pm 4$ & $73 \pm 6$ & & $144 \pm 6^{*}$ & $91 \pm 5^{*}$ & $76 \pm 9$ \\
Daytime & $129 \pm 4$ & $82 \pm 4$ & $74 \pm 7$ & & $144 \pm 6^{*}$ & $93 \pm 5^{*}$ & $77 \pm 9$ \\
Night-time & $120 \pm 7$ & $75 \pm 7$ & $66 \pm 7$ & & $130 \pm 7^{*}$ & $83 \pm 6^{*}$ & $67 \pm 8$ \\
Sleep time & $112 \pm 7$ & $68 \pm 4$ & $61 \pm 6$ & & $120 \pm 6^{*}$ & $74 \pm 6^{*}$ & $62 \pm 5$ \\
Leisure time & $130 \pm 4$ & $83 \pm 4$ & $73 \pm 7$ & & $146 \pm 6^{*}$ & $87 \pm 5^{*}$ & $76 \pm 7$ \\
Work time & $131 \pm 5$ & $84 \pm 5$ & $76 \pm 6$ & & $147 \pm 8^{*}$ & $96 \pm 6^{*}$ & $77 \pm 8$
\end{tabular}

SBP, systolic blood pressure $(\mathrm{mmHg}) ; \mathrm{DBP}$, diastolic blood pressure $(\mathrm{mmHg}) ; \mathrm{HR}$, heart rate (bpm). Values are reported as means \pm SD.

$* \mathrm{P}<0.05, \mathrm{BH}_{1}$ versus $\mathrm{BH}_{2}$ (Student t-test).

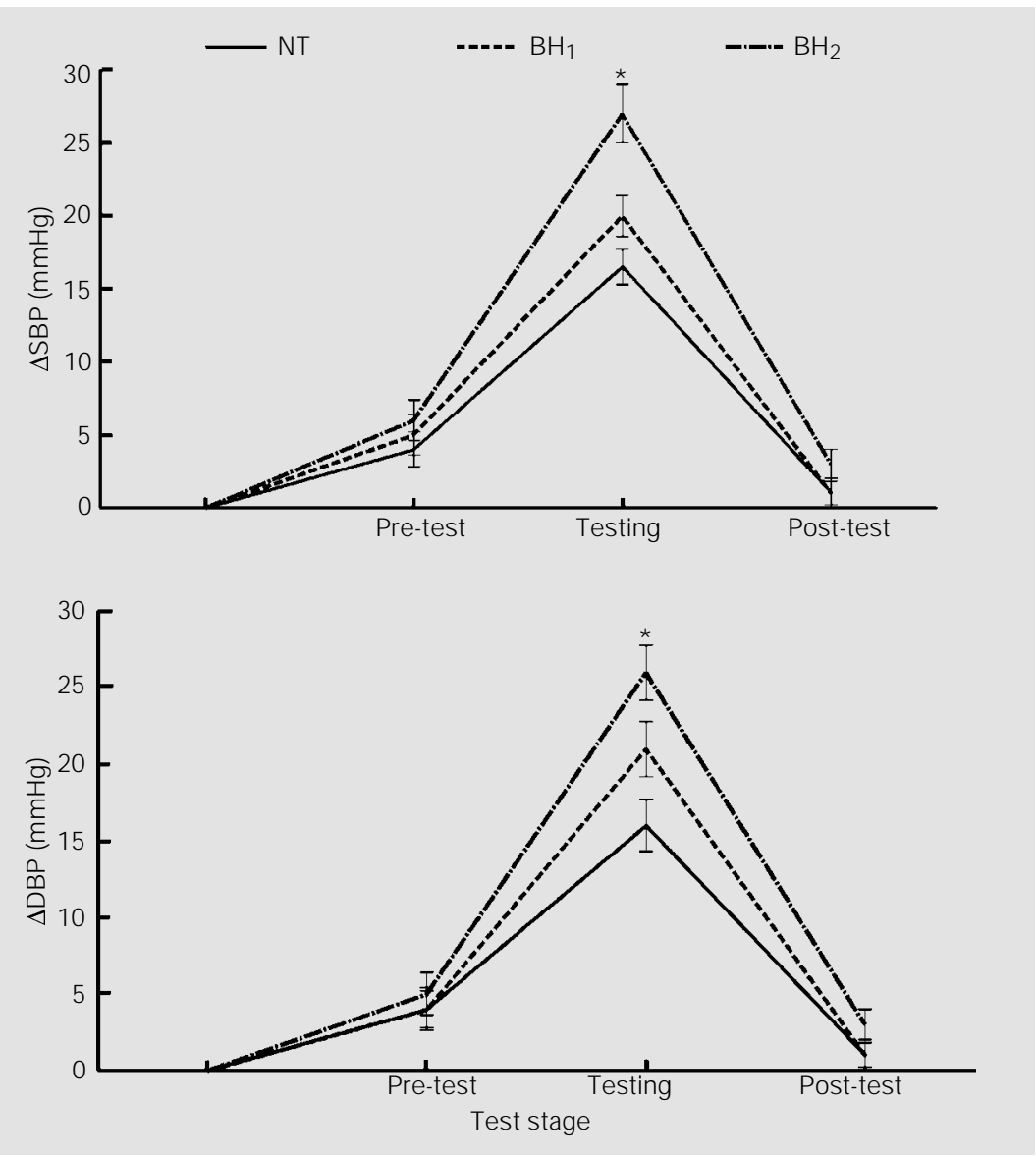

Figure 2. Cold pressor test. Change in systolic blood pressure ( $\triangle \mathrm{SBP}$ ) and diastolic blood pressure $(\triangle \mathrm{DBP})$ recorded for the normotensive (NT), borderline hypertensive with normal $\left(\mathrm{BH}_{1}\right)$ and elevated $\left(\mathrm{BH}_{2}\right)$ monitored blood pressure levels in the pre-test, testing and posttest periods. Values are reported as means $\pm \mathrm{SD}$. $* \mathrm{P}<0.05, \mathrm{BH}_{2}$ compared to $\mathrm{NT}$ and $\mathrm{BH}_{1}$ in the specified test stage (ANOVA and Tukey test). 

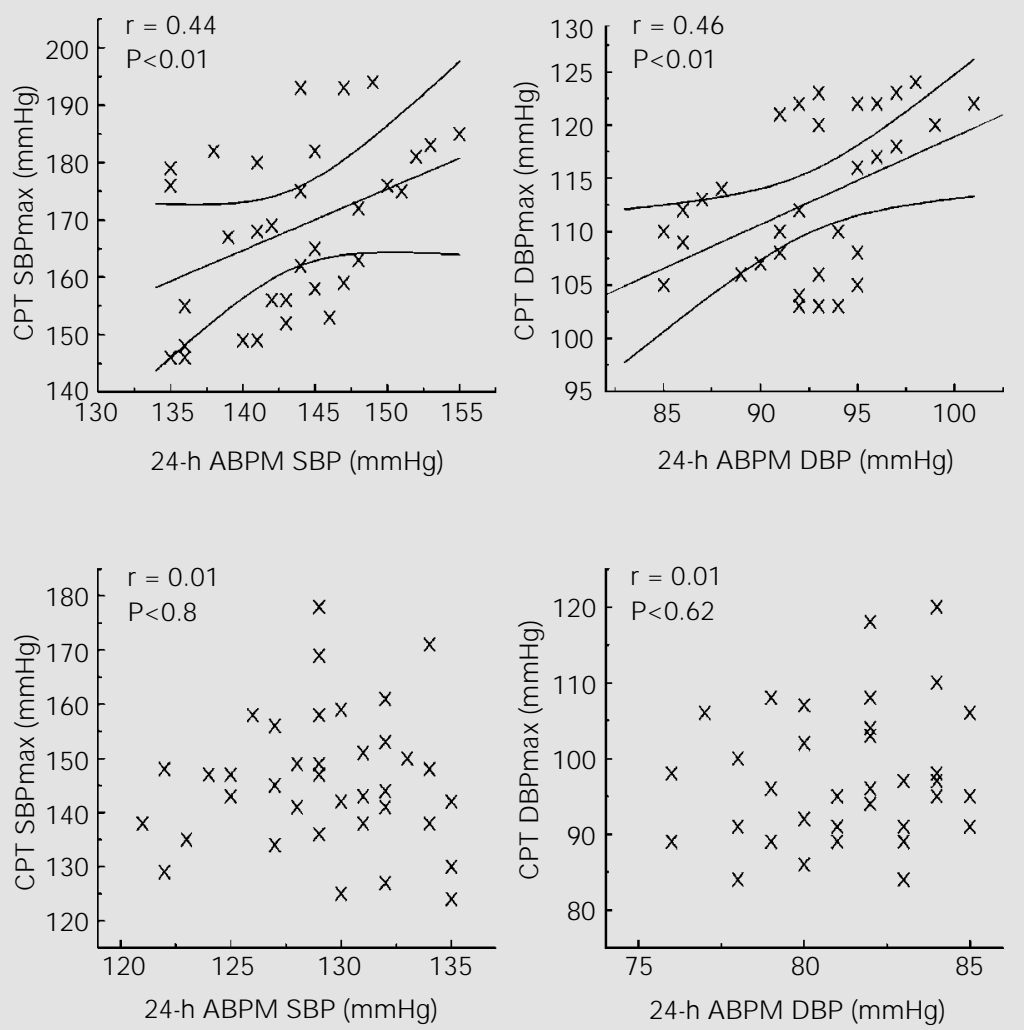

Figure 3. Simple correlation coefficient $(r)$ between 24-h ambulatory blood pressure monitoring (ABPM) SBP and DBP with the maximum values of systolic (SBPmax) and diastolic blood pressure (DBPmax) recorded during the cold pressor test (CPT). The upper panels represent borderline subjects with elevated blood pressure in the 24-h ABPM $\left(\mathrm{BH}_{2}\right)$ and the lower panels borderline subjects with normal blood pressure levels in the 24-h ABPM $\left(\mathrm{BH}_{1}\right)$.

Table 4. Doppler echocardiographic values of normotensive (NT) and borderline hypertensive subjects with normal $\left(\mathrm{BH}_{1}\right)$ and elevated $\left(\mathrm{BH}_{2}\right)$ monitored blood pressure.

\begin{tabular}{lccc}
\hline & $\mathrm{NT}(\mathrm{N}=36)$ & $\mathrm{BH}_{1}(\mathrm{~N}=19)$ & $\mathrm{BH}_{2}(\mathrm{~N}=17)$ \\
\hline LVDd $(\mathrm{mm})$ & $50.6 \pm 2.8$ & $49.5 \pm 3$ & $51 \pm 2.6$ \\
LVMi $\left(\mathrm{g} / \mathrm{m}^{2}\right)$ & $81 \pm 9.3$ & $79 \pm 12$ & $83 \pm 4$ \\
PWT $(\mathrm{mm})$ & $8.9 \pm 0.6$ & $9.0 \pm 0.8$ & $9.1 \pm 0.7$ \\
IVST $(\mathrm{mm})$ & $8.9 \pm 0.6$ & $9.2 \pm 0.8$ & $9.2 \pm 0.8$ \\
RWT & $35 \pm 2$ & $37 \pm 3$ & $36 \pm 4$ \\
FS $(\%)$ & $40 \pm 3$ & $41 \pm 4$ & $43 \pm 3^{*}$ \\
E/A & $1.4 \pm 0.02$ & $1.3 \pm 0.03$ & $1.0 \pm 0.02^{*}$ \\
IVRT (ms) & $79 \pm 7$ & $81 \pm 4$ & $85 \pm 4^{*}$
\end{tabular}

LVDd, left ventricular diastolic diameter; LVMi, left ventricular mass index; PWT, posterior wall thickness; IVST, interventricular septal thickness; RWT, relative wall thickness; FS, fractional shortening; E/A, early to late peak flow velocity ratio; IVRT, isovolumetric relaxation time. Values are reported as means $\pm \mathrm{SD}$.

$* \mathrm{P}<0.05, \mathrm{BH}_{2}$ versus NT and $\mathrm{BH}_{1}$ (ANOVA and Tukey test).
$\mathrm{BP}$ response during the $\mathrm{CPT}$. This pattern of response is frequently associated with an increased systemic vascular resistance and an abnormal vascular function and paralleled by LV adaptations (40). Only in the $\mathrm{BH}_{2}$ group were 24-h ABPM SBP and DBP positively correlated with the maximum values of BP recorded during the CPT. Taken as a whole, these results suggest an integrated pattern of cardiac and vascular adaptation during the development of hypertension.

All subjects in the original $\mathrm{BH}$ group presented an exaggerated $\mathrm{BP}$ response during the CET. However, only those with an elevated monitored BP level presented adaptations in the Doppler echocardiographic indexes and an exaggerated response during the CPT. Our results therefore suggest that $\mathrm{BP}$ elevation during everyday life conditions is a more critical determinant of cardiovascular adaptations than BP reactivity to temporary stressful situations. They also indicate that an accurate BP profile of borderline hypertensive subjects is essential to evaluate the impact of BP levels and reactivity on the cardiovascular system.

\section{References}

1. Kannel WB (1975). Role of blood pressure in cardiovascular disease. Cardiology, 26: 1-10.

2. Perloff DB, Sokolow $M \&$ Cowan $R$ (1983). The prognostic value of ambulatory blood pressure. J ournal of the American Medical Association, 249: 2792-2798.

3. Fagard R, Staessen J A \& Thijs L (1995). The relationships between left ventricular mass and daytime and night-time blood pressures: a meta-analysis of comparative studies. J ournal of Hypertension, 8: 823-829.

4. Pickering TG (1972). Hypertension: definition, natural histories and consequences. American J ournal of Medicine, 52: 570-583.

5. Fuad FM, Trazzi RC, Gallagher J H, MacTyre WJ \& Cook AS (1980). Abnormal left ventricular relaxation in hypertensive patients. Clinical Science, 59: 411S-415S.

6. Parati G, Pomidossi G, Albini F, Malaspina D \& Mancia G (1987). Relationship of 24-hour blood pressure mean and variability to severity of targetorgan damage in hypertension. J ournal of Hypertension, 5: 93-98. 
7. Dlin RN, Hanne N \& Silverberg DS (1983). Follow-up of normotensive men with exaggerated blood pressure response to exercise. American Heart J ournal, 106: 316320.

8. Weder AB \& J ulius S (1985). Behavior, blood pressure variability and hypertension. Psychosomatic Medicine, 47: 406414.

9. Stroop J P (1935). Studies on inference in serial verbal reaction. J ournal of Experimental Psychology, 47: 1207-1211.

10. Matthews KA (1986). Stress testing. In: Matthews KA, Weiss TM, Dembroski D, Falkner B, Manunck SB \& William RB (Editors), Handbook of Stress, Reactivity and Cardiovascular Disease. J ohn Wiley \& Sons, Inc., New York.

11. Sherwood A, Hinderliter AL \& Light KC (1995). Physiological determinants of hyperreactivity to stress in borderline hypertension. Hypertension, 25: 384-390.

12. Mancia G \& Parati G (1987). Reactivity to physical and behavioral stress and blood pressure variability in hypertension. In: J ulius $\mathrm{S} \&$ Basset B (Editors), Handbook of Hypertension. Vol. 9. Elsevier Science Publishing, New York.

13. Naughton J P, Sevullus G \& Balke B (1963). Physiological response of normal and pathological subjects to a modified work capacity test. J ournal of Sports Medicine and Physical Fitness, 31: 201-207.

14. Manolio TA, Burke GL, Savage PJ , Sidney S, Gardin J M \& Berman A (1994). Exercise blood pressure response and 5-year risk of elevated blood pressure in a cohort of young adults. American J ournal of Hypertension, 7: 234-241.

15. Mundal R, Kjeldsen SE, Sandvik $L$, Erikssen G, Thaulow E \& Erikssen J (1994). Exercise blood pressure predicts cardiovascular mortality in middle-aged men. Hypertension, 24: 56-62.

16. Lafleche $A B$, Pannier BM, Laloux $B$ \& Safar ME (1999). Arterial response during cold pressure test in borderline hypertension. American J ournal of Physiology, 275: $\mathrm{H} 409-\mathrm{H} 415$.

17. Toto-Moukouo J , Um J P, J on J P \& Hagbe $P$ (1993). Hemodynamic reactivity factors to cold pressor in blacks with sustained essential hypertension. American J ournal of Hypertension, 6: 824-829.

18. Eliason K, Hjemdhal P \& Kahan T (1983). Circulatory sympathoadrenal and psychological reactions to stress. J ournal of $\mathrm{Hy}$ pertension, 1: 131-139.

19. J ern S, Bergbrant A, Hedner $T \&$ Hansson L (1995). Enhanced pressor responses to experimental and daily-life stress in borderline hypertension. J ournal of Hypertension, 1: 69-79.

20. Fragola PV, Romitelli S, Moretti A, Michisanti M \& Cannata D (1993). Precursors of established hypertension in borderline hypertensives. A two-year follow-up. International J ournal of Cardiology, 2: 113119.

21. Kohler T, Fricke $M$, Ritz T \& Scherbaum N (1997). Psychophysiological reactivity of borderline hypertensives and their recovery after mental stress. Psychotherapy and Psychosomatics, 5: 261-267.

22. Mancia G (1990). Ambulatory blood pressure monitoring: research and clinical applications. J ournal of Hypertension, 8: S1S13.

23. Pickering TG (1990). Hypertension, natural histories and consequences. In: Laragh J H \& Brenner MB (Editors), Hypertension: Pathophysiology, Diagnosis and Management. Raven Press, New York.

24. World Health Organization - International Society of Hypertension (1999). Guidelines for the management of hypertension. J oumal of Hypertension, 17: 151183.

25. Perloff DB, Grim C, Flack J, Frolich ED, Hill $M, M c D o n a l d ~ M \&$ Morgenstem $Z$ (1993). Human blood pressure determination by sphygmomanometry. Circulation, 5: 2460-2470.

26. Chaitman BR (1997). Exercise stress testing. In: Antman EE, Bain DS, Barold SS \& Braunwald E (Editors), Heart Disease. A Textbook of Cardiovascular Medicine. W.B. Saunders, Philadelphia.

27. Bruce RA (1977). Methods of exercise testing: step test, bicycle, treadmill and isometrics. In: Amsterdam EA, Wilmore $\mathrm{J} \mathrm{H} \&$ De Maria NA (Editors), Exercise in Cardiovascular Health and Disease. York Medical Books, New York.

28. ISH Scientific Committee (1990). Consensus document on non-invasive ambulatory blood pressure monitoring. J ournal of Hypertension, 8 (Suppl 6): S136-S140.

29. Hines EA \& Brown GE (1936). The cold pressor test for measuring the reactivity of the blood pressure: data concerning 571 normal and hypertensive subjects. American Heart J ournal, 11: 1-9.

30. Sahn DJ, DeMaria A, Kisslo J, Weyman A $\&$ The Committee on M-mode Standardization of the American Society of Echocardiography (1978). Recommendations regarding quantification in $\mathrm{M}$-mode echocardiography: results of a survey of echocardiographic measurements. Circu- lation, 58: 1072-1083.

31. Devereaux RB, Alonso DR, Lutas EM, Gottlieb GJ , Campo E, Sachs I \& Reichek N (1986). Echocardiographic assessment of left ventricular hypertrophy. American J ournal of Cardiology, 57: 450-458.

32. Graettinger WF, Weber MA, Gardin J M \& Knoll M (1987). Diastolic pressure as a determinant of left ventricular filling in normotensive adolescents. J ournal of the American College of Cardiology, 10: 12801285.

33. Everson SA, Kaplan GA, Goldenberg DE \& Salonen TJ (1996). Anticipatory blood pressure to exercise predicts future high blood pressure in middle-age men. Hypertension, 27: 1059-1064.

34. Mantero A, Gentile F, Gualtierotti $C$ Azzolini M, Barbiere P, Berett L, Casazza F, Corno R, Lippolis A, Lombroso $S \&$ Ornaghi M (1995). Left ventricular diastolic parameters in normal subjects from 20 to 80 years old. European Heart J ournal, 16: 94-105.

35. Graettinger WF, Neutel J M, Smith HG \& Weber MA (1987). Left ventricle diastolic filling alterations in normotensive young adults with family history of systemic hypertension. American J ournal of Cardiology, 10: 1280-1285.

36. Mabaroti C, Genovessi-Ebert A, Giaconi S, Michelassi C \& Ghione S (1989). Echodoppler assessment of left ventricular filling in borderline hypertension. American J ournal of Hypertension, 2: 891897.

37. Sung $B H$, Lovallo $W R$, Teague $S M$, Pincomb GA, Wilmore J $\mathrm{H} \&$ Wilson $M F$ (1999). Cardiac adaptation to increased systemic blood pressure in borderline hypertensive men. American J ournal of Cardiology, 72: 407-412.

38. Diazuzumba SB, DiPette DJ \& Corman C (1986). Left ventricular filling characteristics in mild untreated hypertension. Hypertension, 8: I-56-I-60.

39. Choong CY, Herrman HC, Weyman AE \& Fifer MA (1987). Preload dependence of Doppler derived indexes of left ventricular diastolic function in humans. J ournal of the American College of Cardiology, 10: 800-808.

40. Boutouyrie P, Laurent S, Gired X, Benetos A, Lacolley P, Abergel E \& Safar M (1995). Common carotid artery stiffness and patterns of left ventricular hypertrophy in hypertensive patients. Hypertension, 25: 651-659. 